\title{
Effects of red pepper added to high-fat and high-carbohydrate meals on energy metabolism and substrate utilization in Japanese women
}

\author{
Mayumi Yoshioka ${ }^{1}$, Sylvie St-Pierre ${ }^{1}$, Masashige Suzuki ${ }^{2}$ and Angelo Tremblay ${ }^{1 *}$ \\ ${ }^{1}$ Division of Kinesiology, PEPS, Laval University, Ste-Foy, Québec, Canada GIK 7P4 \\ ${ }^{2}$ Institute of Health and Sport Sciences, University of Tsukuba, Tsukuba, Ibaraki 305, Japan
}

(Received 23 September 1997 - Revised 26 May 1998 - Accepted 10 June 1998)

\begin{abstract}
The effects of dietary red pepper added to high-fat (HF) and high-carbohydrate (HC) meals on energy metabolism were examined in thirteen Japanese female subjects. After ingesting a standardized dinner on the previous evening, the subjects took an experimental breakfast $(1883 \mathrm{~kJ})$ under the following four conditions: HF meal, HF and red-pepper $(10 \mathrm{~g})$ meal, HC meal, or HC and red-pepper meal. Palatability of the experimental meals was measured immediately after the meals. Expired air was collected before and for $210 \mathrm{~min}$ after the meal to determine energy expenditure and macronutrient oxidation. Diet-induced thermogenesis was significantly higher after the HC meals than after the HF meals. Lipid oxidation was significantly lower and carbohydrate oxidation was significantly higher after the HC meals than after the HF meals. Addition of red pepper to the experimental meals significantly increased diet-induced thermogenesis and lipid oxidation, particularly after the HF meal. On the other hand, carbohydrate oxidation was significantly decreased by the addition of red pepper to the experimental meals. Addition of red pepper to the HC meal increased the perceived oiliness of the meal to the same level as that of the HF meals. These results indicate that red pepper increases diet-induced thermogenesis and lipid oxidation. This increase in lipid oxidation is mainly observed when foods have a HF content whereas the increase in the perceived oiliness of the meal was found under the HC meal conditions.
\end{abstract}

Red pepper: Diet-induced thermogenesis: Lipid oxidation: Palatability

Dietary fat intake has markedly increased with industrialization in many countries (Leaf \& Weber, 1987). An increase in the fat content of the diet has been shown to be associated with increases in daily energy intake (Lissner et al. 1987; Tremblay et al. 1989, 1991) and body fatness (Romieu et al. 1988; Tremblay et al. 1989) in human subjects. In rodents, high-fat (HF) diets have been shown to produce obesity independently of total energy intake (Oscai et al. 1984; Hill et al. 1992). This positive energy balance resulting from HF feeding is not clearly explained, but experimental evidence suggests that it could be attributable to the high energy density of dietary fat (Porikos et al. 1977; Duncan et al. 1983) and the inability of fat to increase fat oxidation acutely (Flatt et al. 1985; Schutz et al. 1989; Bennett et al. 1992; Horton et al. 1995). Diet composition can also affect total energy intake (Tremblay et al. 1989; Thomas et al. 1992) and nutrient balance in human subjects without changing total energy expenditure (Abbott et al. 1990; Hill et al. 1991). In addition, human subjects increase carbohydrate oxidation and total energy expenditure in response to excess carbohydrate (Acheson et al. 1988), but fail to increase fat oxidation or energy expenditure in response to excess fat (Flatt et al. 1985; Schutz et al. 1989; Bennett et al. 1992). This suggests that excess dietary fat leads to greater fat accumulation than does excess dietary carbohydrate.

The sympathetic nervous system (SNS) is thought to play an important role in the regulation of energy and substrate balance. For example, the thermic effect of nutrients can be partitioned into obligatory and facultative components of thermogenesis (Acheson et al. 1983, 1984). The facultative component appears to be sympathetically mediated because it can be abolished by $\beta$-adrenergic antagonists (Acheson et al. 1983, 1984). Tappy et al. (1995) reported that SNS stimulation increased plasma noradrenaline by $27 \%$ and lipid oxidation by $72 \%$ whereas it reduced glucose oxidation by $14 \%$ in the postprandial state. This indicates that SNS stimulation can preferentially increase lipid oxidation postprandially, suggesting that it might be possible to correct a state of impaired lipid oxidation under

\footnotetext{
Abbreviations: DIT, diet-induced thermogenesis; HC, high carbohydrate; HF, high fat; LPL, lipoprotein lipase; RP, red pepper; SNS, sympathetic nervous system.

*Corresponding author: Dr Angelo Tremblay, fax +1 418656 2441, email ANGELO.TREMBLAY@ KIN.MSP.ULAVAL.CA
} 
HF diet conditions by stimulating the SNS in the postprandial phase. Kawada and colleagues (Kawada et al. 1986a,b, 1988, 1991; Watanabe et al. 1987a,b, 1988a,b) showed that capsaicin, which is the major pungent principle in various Capsicum fruits (hot red pepper), enhanced energy and lipid metabolism in rats by stimulating the sympathoadrenal system. In a recent human study, the increase in energy expenditure immediately after a meal containing red pepper (RP) was probably explained by $\beta$-adrenergic stimulation (Yoshioka et al. 1995). Therefore, we investigated the effects of RP added to HF and highcarbohydrate (HC) meals on postprandial energy metabolism. Since an increase in the palatability of a meal can increase diet-induced thermogenesis (DIT) (Raben et al. 1994), we also investigated the effect of RP added to HF and HC meals on palatability and DIT.

\section{Methods}

\section{Subjects}

Thirteen healthy Japanese women volunteered to participate in this study. The participants were asked to maintain their regular dietary habits and to abstain from alcohol and caffeine intake on the day before the investigation. Strenuous physical activity was not allowed for $2 \mathrm{~d}$ before each experimental session. All subjects were tested during the follicular phase of the menstrual cycle (two separate days in a row) and they participated in four testing sessions which were separated by at least $3 \mathrm{~d}$ from each other. The written consent of each subject was obtained before admission to the study whose procedures conformed to the Declaration of Helsinki. Subject characteristics are presented in Table 1.

In three subjects, body density was determined by the underwater weighing technique (Behnke \& Wilmore, 1974) and percentage body fat was derived from body density (Siri, 1956). Pulmonary residual volume was measured using the He dilution method (Spiroflow Morgan, Chatham, Kent, UK) (Meneely \& Kaltreider, 1949). In ten subjects, percentage body fat was measured using bioelectrical impedance (Body Fat Analyzer TBF-102, Tanita, Tokyo, Japan).

\section{Experimental protocol and measurements}

The experimental protocol was designed to evaluate the effects of dietary RP and meal composition on postprandial energy metabolism. Powdered RP (Saemaul Kongjang) was added to the experimental meals and was mixed in order to distribute it evenly throughout the meal. The experimental meals consisted of a stir fry of rice, scallops, shrimps, bacon, green peppers, green peas, onions and tomatoes, sauted in

Table 1. Characteristics of the subjects $(n$ 13)

\begin{tabular}{lccc}
\hline Variable & Mean & SD & Range \\
\hline Age (years) & 25.8 & 2.8 & $22-30$ \\
Weight (kg) & 54.2 & 6.4 & $45-63$ \\
Height (m) & 1.572 & 0.045 & $1.50-1.64$ \\
Body fat (\%) & 25.3 & 4.7 & $19-34$ \\
\hline
\end{tabular}

vegetable oil. The subjects consumed a standardized dinner $(15,25$ and $60 \%$ energy from protein, fat and carbohydrate, respectively) on the day preceding each session. On the next morning, they randomly participated in one of the four test sessions consisting of the measurements of energy expenditure and carbohydrate and lipid oxidation before and for 210 min after the experimental breakfast $(1883 \mathrm{~kJ} / 600 \mathrm{~g}$ including drinking water). This meal differed in each session according to the following specifications: HF meal (\% energy: protein 15, fat 45, carbohydrate 40) $\mathrm{HF}$ and $\mathrm{RP}$ $(10 \mathrm{~g})$ meal (HF-RP), HC meal (\% energy: protein 15, fat 25, carbohydrate 60), and $\mathrm{HC}$ and RP meal (HC-RP). Immediately after each experimental meal, expired air was collected for $10 \mathrm{~min}$ (time $30 \mathrm{~min}$ in Figs. 1, 2, 3 and 4). The subsequent air collections were performed every $10 \mathrm{~min}$ for the first hour after the experimental meals and then every $30 \mathrm{~min}$ from $90 \mathrm{~min}$ to $210 \mathrm{~min}$ after the experimental meals. In ten subjects, the pulmonary ventilation and the fractions of $\mathrm{O}_{2}$ and $\mathrm{CO}_{2}$ in expired air were measured with a spirometer (Fukuda Irika kenkyujo CR-20; Nagareyama, Chiba, Japan) and paramagnetic and infrared analysers (Perkin Elmer 1100 Medical GAS Analyzer; Torrance, CA, USA) respectively. In three subjects, an open-circuit gas analysis system (Hartmann \& Braun Uras 10E; Bartlesvile, Industriestrasse 28, Eschborn, Germany) was used. Lipid and carbohydrate oxidation rates were estimated by using the tables of Lusk (1931), while assuming that $10 \%$ of resting metabolic rate was covered by protein oxidation, as previously described (Schutz \& Tremblay, 1991).

The palatability of experimental meals was measured immediately after the breakfast by using a $150 \mathrm{~mm}$ visual analogue scale which was modified from the method described by Hill \& Blundell (1986). Appearance, smell and taste of the experimental meal were assessed using the question 'How did you feel about the appearance, smell and taste of the meal?' and were coded from 'very bad' to 'very good'. Oiliness of the experimental meal was assessed using the question 'How much did you feel the oiliness of the meal?' and was coded from 'light' to 'greasy'. The hot sensation produced by the experimental meal was assessed using the question 'How much did you feel a hot sensation of the meal?' and was coded from 'not hot at all' to 'very hot'. The size of the experimental meal was assessed using the question 'How did you feel about the amount of the meal?' and was coded from 'too small' to 'too much'. The oiliness, hotness and size of the experimental meals compared with subjects' habitual meals were assessed using the question 'How did you feel the oiliness, hot sensation and amount of the experimental meal compared to your habitual meal?' and were coded from 'light' to 'greasy', 'not hot at all' to 'very hot' and 'too small' to 'too much' respectively.

\section{Statistical analysis}

All results obtained with the analogue scale were converted to scores ranging from 0 to 100 for statistical analysis (low scores on the palatability scale indicate poor palatability).

A three-way ANOVA with repeated measurements was used to determine effects of diet composition, RP and time as well as their interactions. We also used a two-way ANOVA to determine the effects of diet composition and 
Table 2. Palatability† of high-fat (HF) and high-carbohydrate $(\mathrm{HC})$ meals with or without red pepper (RP) (Mean values and standard deviations for thirteen subjects)

\begin{tabular}{|c|c|c|c|c|c|c|c|c|c|c|c|}
\hline \multirow[t]{2}{*}{ Diet... } & \multicolumn{2}{|c|}{$\mathrm{HF}$} & \multicolumn{2}{|c|}{$\mathrm{HF}+\mathrm{RP}$} & \multicolumn{2}{|c|}{$\mathrm{HC}$} & \multicolumn{2}{|c|}{$\mathrm{HC}+\mathrm{RP}$} & \multicolumn{3}{|c|}{$\begin{array}{l}\text { Statistical significance of } \\
\text { effect of: }\end{array}$} \\
\hline & Mean & SD & Mean & SD & Mean & SD & Mean & SD & Diet & $\mathrm{RP}$ & Diet $\times \mathrm{RP}$ \\
\hline Appearance & $80 \cdot 7$ & $9 \cdot 8$ & 58.5 & $18 \cdot 1$ & $72 \cdot 3$ & $26 \cdot 8$ & $57 \cdot 2$ & $17 \cdot 0$ & & * & \\
\hline Smell & $70 \cdot 6$ & $18 \cdot 2$ & 54.0 & 12.5 & $58 \cdot 7$ & $20 \cdot 2$ & 53.2 & $9 \cdot 4$ & * & * & \\
\hline Taste & $82 \cdot 9$ & $14 \cdot 2$ & $56 \cdot 5$ & $26 \cdot 2$ & 73.2 & $17 . \overline{6}$ & 54.2 & 21.3 & & * & \\
\hline Amount & $53 \cdot 6$ & $16 \cdot 4$ & $62 \cdot 2$ & $19 \cdot 4$ & $67 \cdot 8$ & $20 \cdot 5$ & $74 \cdot 1$ & $21 \cdot 8$ & * & & \\
\hline \multicolumn{12}{|c|}{ Experimental meals compared with daily meals } \\
\hline Oiliness & 67.9 & $27 \cdot 4$ & 66.4 & $24 \cdot 6$ & 43.3 & $22 \cdot 8$ & 62.5 & $24 \cdot 4$ & & & * \\
\hline Hot sensation & 14.9 & $22 \cdot 9$ & 93.9 & 8.2 & $22 \cdot 8$ & $22 \cdot 1$ & $92 \cdot 8$ & $16 \cdot 0$ & & * & \\
\hline Amount & $56 \cdot 6$ & $15 \cdot 8$ & 60.4 & $17 \cdot 8$ & 68.1 & $19 \cdot 2$ & 71.5 & $20 \cdot 6$ & * & & \\
\hline
\end{tabular}

${ }^{*} P<0.05$ (two-way ANOVA).

†Palatability was assessed on a scale of 0-100 (low scores show poor palatability).

$\mathrm{RP}$ as well as the diet composition $\times \mathrm{RP}$ interaction on the palatability of experimental meals as well as changes in energy expenditure and substrate oxidation. When the ANOVA revealed a significant effect, a contrast analysis was applied to identify which conditions were different from each other. Differences were considered to be statistically significant at $P<0.05$.

\section{Results}

The palatability of the experimental meals is shown in Table 2. Appearances of the RP meals were significantly less agreeable than those of the meals not containing RP (control meals). However, the scores for appearance of the RP meals were greater than 50, which means that they were perceived as agreeable. Smells of the HF meals were significantly more agreeable than those of the HC meals. The HF meal without RP had a more agreeable smell compared with the other three experimental meals and this effect was close to conventional statistical significance $(P=0.06)$. Tastes of RP meals were significantly less agreeable than those of the control meals, but were not considered disagreeable. As expected, the oiliness of the HF meals was significantly more pronounced than that of the $\mathrm{HC}$ meals. The addition of RP to the HC meal significantly increased perceived oiliness to the same level as the HF and HF-RP meals. Hot sensations of the RP meals were significantly more pronounced than those of the control meals. The hotness of the experimental meals compared with the subjects' habitual meals was coded as intermediate between that of the RP meals and that of the control meals. The amounts of food in the HC meals were coded as greater than those of the HF meals despite the fact that total weights of meal were identical for all four experimental meals, since we adjusted the weight of meal with the amount of drinking water. The experimental meals, particularly the $\mathrm{HC}$ meals, were perceived to be larger than the usual meals of subjects.

The three-way ANOVA revealed that postprandial $\mathrm{O}_{2}$ consumption was significantly affected by time, diet composition $\times$ time interaction and $\mathrm{RP} \times$ time interaction (Fig. 1(a)). Postprandial $\mathrm{O}_{2}$ consumption after the $\mathrm{HC}$ meals was significantly higher than after the HF meals from 50 to $150 \mathrm{~min}$. RP significantly increased postprandial $\mathrm{O}_{2}$ consumption from 60 to $180 \mathrm{~min}$. As for $\mathrm{O}_{2}$ consumption, diet composition, RP, time, diet composition $\times$ time interaction and $\mathrm{RP} \times$ time interaction exerted a significant effect on RQ (Fig. 1(b)). Significantly higher RQ were found after the HC meals than after the HF meals, particularly between 60 and $210 \mathrm{~min}$ postprandially. The addition of RP to the experimental meals significantly lowered RQ compared with the control meals between 30 and 60 min postprandially.

Variations in postprandial energy expenditure are shown in Fig. 2. The three-way ANOVA revealed that postprandial energy expenditure was significantly modified by diet composition, time, diet composition $\times$ time interaction and $\mathrm{RP} \times$ time interaction (Fig. 2(a)). Significantly higher energy expenditure after the HC meals compared with the HF meals was observed between 50 and $150 \mathrm{~min}$. The addition of RP to the experimental meals significantly increased energy expenditure compared with the control meals at 90, 150 and $180 \mathrm{~min}$ postprandially. The absence of a significant effect of RP in the early postprandial period was partly explained by the fact that the energy equivalent of $\mathrm{O}_{2}$ during this period, as reflected by $\mathrm{RQ}$, was lower than for the control meals. The two-way ANOVA revealed that DIT, i.e. the increase in resting energy expenditure induced by food intake, was significantly modified by diet composition, RP, and diet composition $\times \mathrm{RP}$ interaction (Fig. 2(b)). DIT was significantly higher after the HC meals than after the HF meals, and it was significantly increased by the addition of RP to the experimental meals. The impact of RP on DIT was more pronounced in the HF meal. Under these conditions, the effect of RP was sufficiently high to eliminate the difference between the HF and HC meals.

Variations in postprandial lipid oxidation rate are illustrated in Fig. 3. As for energy expenditure, diet composition, $\mathrm{RP}$, time, diet composition $\times$ time interaction and $\mathrm{RP} \times$ time 

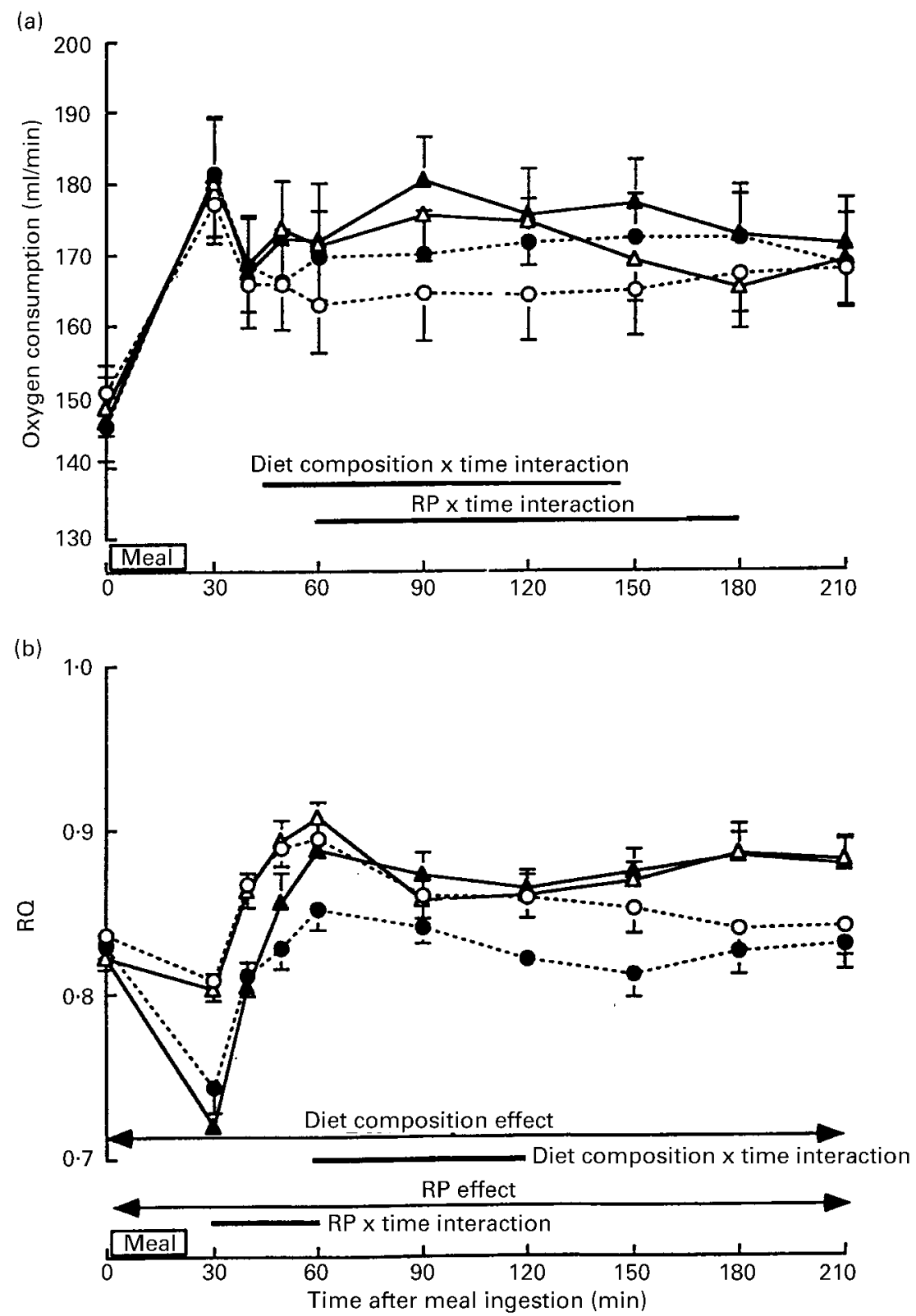

Fig. 1. (a) Oxygen consumption and (b) $R Q$ values measured over 210 min following ingestion of experimental meals: $(\cdots \bigcirc \cdots)$, high fat; $(\cdots \cdots)$, high fat plus red pepper (RP); $(-\triangle)$, high carbohydrate; $(--)$, high carbohydrate plus RP. Values are means for thirteen subjects, with their standard errors represented by vertical bars. Three-way ANOVA revealed that postprandial oxygen consumption was significantly affected by time, diet composition $\times$ time interaction and $R P \times$ time interaction. $R Q$ was significantly affected by time, diet composition, RP, diet composition $\times$ time interaction and $\mathrm{RP} \times$ time interaction.

interaction exerted significant effects on this variable (Fig. 3(a)). Lipid oxidation was significantly greater after the HF meals than after the HC meals at 60, 120, 150, 180 and $210 \mathrm{~min}$ postprandially. The addition of RP to the experimental meals significantly increased lipid oxidation compared with the control meals at 30,40, 50, 60, 120 and 150 min after meals. The meal-induced change in lipid oxidation was also modified by diet composition, RP, and diet composition $\times$ RP interaction (Fig. 3(b)). The change in lipid oxidation was significantly greater in the HF meals than in the HC meals, and it was significantly increased by the addition of RP to the experimental meals. The addition of RP to the HF meal significantly increased dietinduced lipid oxidation more than did the addition of RP to the $\mathrm{HC}$ meal.

Variations in postprandial carbohydrate oxidation are depicted in Fig. 4. Carbohydrate oxidation was affected by diet composition, RP, time, diet composition $\times$ time interaction and RP $\times$ time interaction (Fig. 4(a)). After the $\mathrm{HC}$ meals, the higher carbohydrate oxidation compared with 

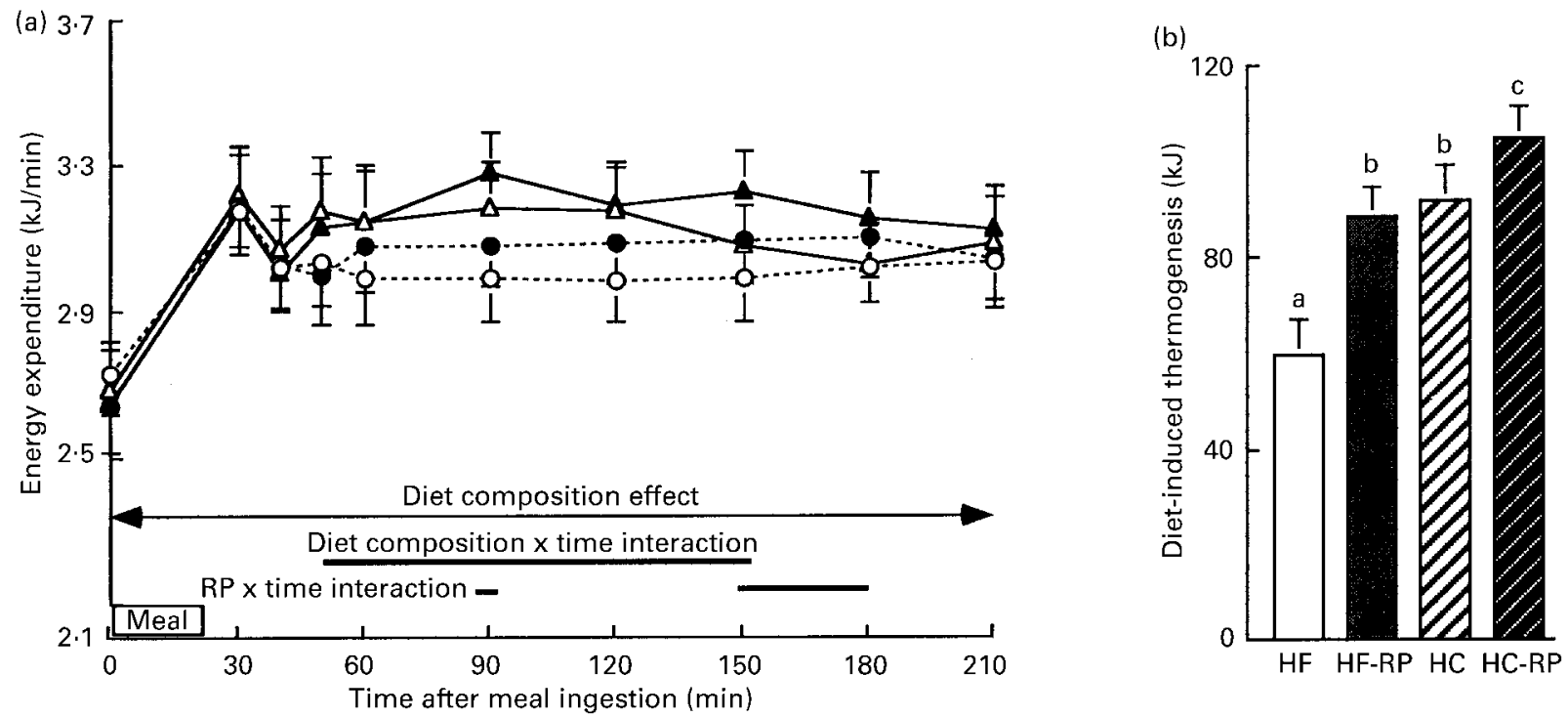

Fig. 2. (a) Energy expenditure measured for $210 \mathrm{~min}$ following ingestion of experimental meals: $(\cdots \bigcirc \cdots)$, high fat; $(\cdots \bullet \cdots)$, high fat plus red pepper (RP); $(--)$, high carbohydrate; $(--)$, high carbohydrate plus RP. Values are means for thirteen subjects, with their standard errors represented by vertical bars. Three-way ANOVA revealed that postprandial energy expenditure was significantly modified by time, diet composition, diet composition $\times$ time interaction and RP $\times$ time interaction. (b) Diet-induced thermogenesis following high-fat (HF) and high-carbohydrate $(\mathrm{HC})$ meals with and without RP. Values are means for thirteen subjects, with their standard errors represented by vertical bars. ${ }^{\mathrm{a}, \mathrm{b}, \mathrm{c}}$ Mean values not sharing a common letter were significantly different, $P<0.05$.

the HF meal conditions was mainly observed between 50 and $210 \mathrm{~min}$. The lowering effect of RP on carbohydrate oxidation compared with the control meals was significant from 30 to $60 \mathrm{~min}$ after the meal. The two-way ANOVA showed that diet composition, RP and diet composition $\times$ $\mathrm{RP}$ interaction also influenced the response of carbohydrate oxidation to the experimental meals (Fig. 4(b)). Mealinduced carbohydrate oxidation was significantly higher after the HC meals than after the HF meals, and it was significantly decreased by the addition of RP to the experimental meals.
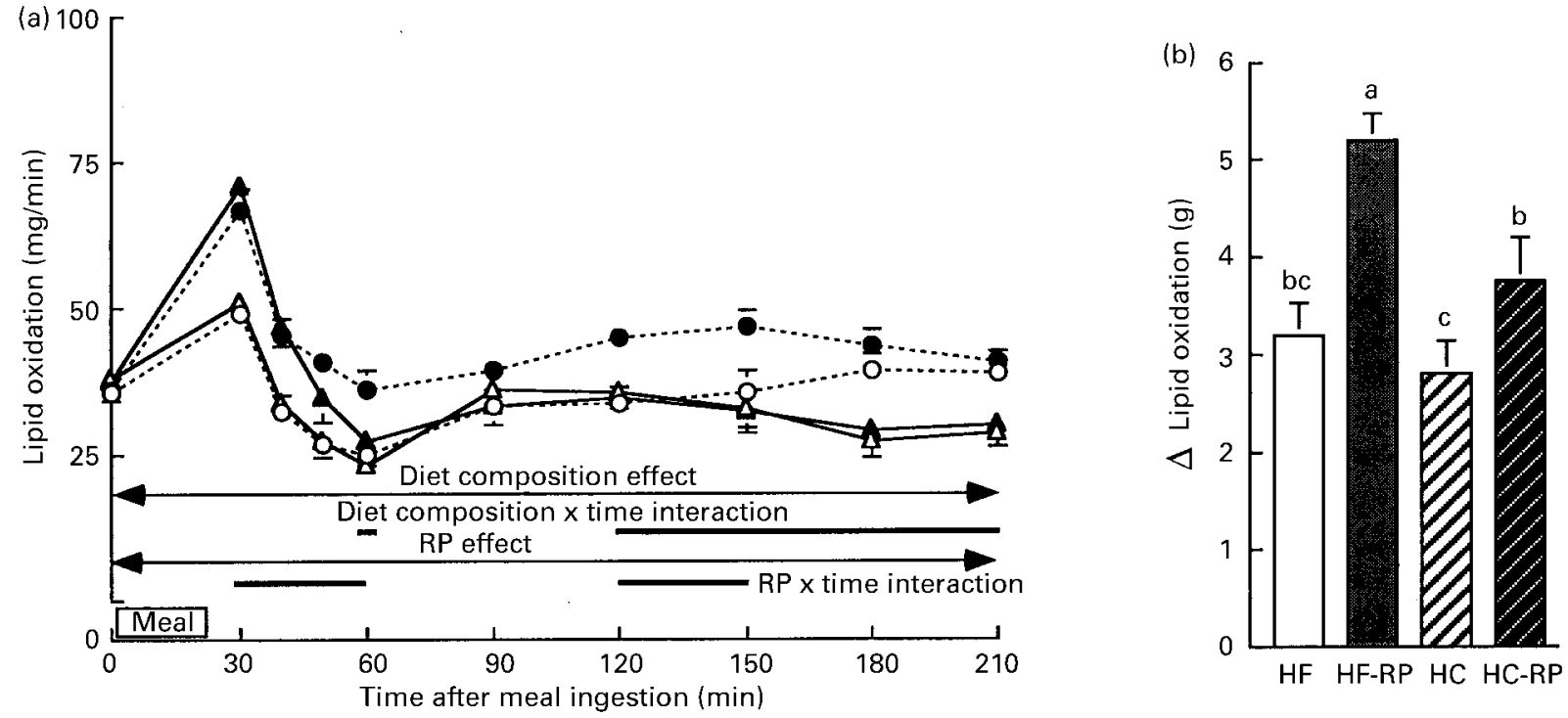

Fig. 3. (a) Lipid oxidation measured for 210 min following ingestion of experimental meals: $(\cdots \bigcirc \cdots)$, high fat; $(\cdots \bullet \cdots)$, high fat plus red pepper (RP); $(-\backsim)$, high carbohydrate; $(--)$, high carbohydrate plus RP. Values are means for thirteen subjects, with their standard errors represented by vertical bars. Three-way ANOVA revealed that postprandial lipid oxidation was significantly modified by time, diet composition, RP, diet composition $\times$ time interaction and RP $\times$ time interaction. (b) Change in lipid oxidation following high-fat (HF) and high-carbohydrate (HC) meals with and without RP. Values are means for thirteen subjects, with their standard errors represented by vertical bars. ${ }^{\mathrm{a}, \mathrm{b}, \mathrm{c}} \mathrm{Mean}$ values not sharing a common letter were significantly different, $P<0.05$. 

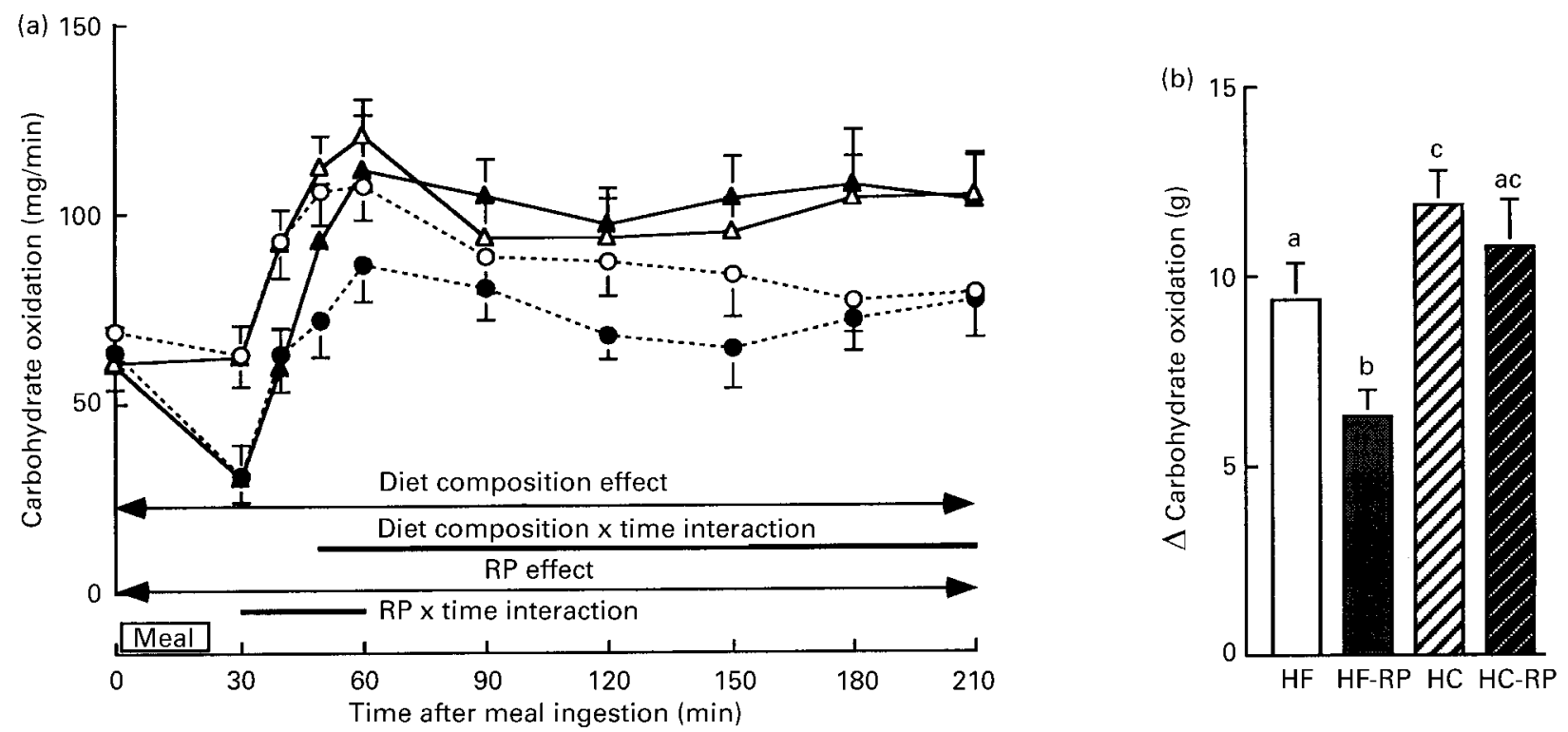

Fig. 4. (a) Carbohydrate oxidation measured for $210 \mathrm{~min}$ following ingestion of experimental meals: $(\cdots \bigcirc \cdots)$, high fat; $(\cdots \bullet \cdots)$, high fat plus red pepper (RP); $(--)$, high carbohydrate; $(-\boldsymbol{-})$, high carbohydrate plus RP. Values are means for thirteen subjects, with their standard errors represented by vertical bars. Three-way ANOVA revealed that postprandial carbohydrate oxidation was significantly modified by time, diet composition, RP, diet composition $\times$ time interaction and RP $\times$ time interaction. (b) Change in carbohydrate oxidation following high-fat (HF) and high-carbohydrate $(\mathrm{HC})$ meals with and without RP. Values are means for thirteen subjects, with their standard errors represented by vertical bars. ${ }^{\mathrm{a}, \mathrm{b}, \mathrm{c}}$ Mean values not sharing a common letter were significantly different, $P<0.05$.

\section{Discussion}

\section{Palatability of the experimental meal}

It is well known that the palatability of the diet can increase DIT (Raben et al. 1994). However, palatability of the experimental meals was greater for the HF meals and was lowered by the addition of RP to the experimental meals. Moreover, DIT was lower after the HF meals than after the HC meals and was increased by the addition of RP to the experimental meals. Thus, it must be concluded that the lower DIT observed after the HF meals and the increase in DIT resulting from the addition of RP to the experimental meals were not due to the palatability of the experimental meals. Interestingly, when we asked whether the oiliness of the experimental meals was comparable with that of the subjects' habitual meals, the addition of RP to the $\mathrm{HC}$ meals led to a significant increase in the perceived oiliness to the same level as the HF and the HF-RP meals. The taste preference for fat has been found to be increased in obese and post-obese individuals (Drewnowski \& Greenwood, 1983) and this was confirmed by recent experimental data (Drewnowski et al. 1992). If the phenomenon described earlier occurs in obese and post-obese individuals, the addition of RP to a low-fat meal might be an alternative way to increase the perceived oiliness of the diet without increasing fat intake. This issue is of potential clinical relevance and should be the subject of further investigations.

\section{Effects of high-fat and high-carbohydrate meals}

Warwick \& Schiffman (1992) have reviewed the literature pertaining to effects of dietary fat on energy intake and body weight in human subjects and laboratory animals and have concluded that both energy intake and energy expenditure are biased towards weight gain when a HF diet is consumed, and that the high energy density of HF diets plays a primary role in weight gain. In the present study, postprandial energy expenditure and carbohydrate oxidation rate were lower after the HF meals, whereas a higher lipid oxidation rate was found after the HF-RP meal. These results are consistent with previous findings (Flatt et al. 1985; Bennett et al. 1992) and support the idea that energy expenditure is biased towards weight gain when a HF diet is consumed (Warwick \& Schiffman, 1992).

\section{Effects of red pepper}

Kawada and coworkers (Watanabe et al. 1987a,b, 1988a,b; Kawada et al. 1988) have reported that capsaicin enhances the catecholamine secretion from the adrenal medulla in rats, mainly through activation of the central nervous system (Watanabe et al. 1988a, b), and results in an increase in $\mathrm{O}_{2}$ consumption (Kawada et al. 1986b). In a recent human study, we observed that a diet containing RP increased $\mathrm{O}_{2}$ consumption and energy expenditure by about $30 \%$. In addition, this increase was abolished by $\beta$-adrenergic blockade (Yoshioka et al. 1995). In the present study, the addition of RP to the experimental meals increased postprandial energy expenditure. Moreover, the addition of RP to the $\mathrm{HF}$ meal increased DIT as much as did the HC meal. Therefore, dietary RP has a beneficial effect on postprandial energy expenditure and corrects the weak thermogenic effect of a HF diet.

It has been shown that RQ is immediately increased when capsaicin is injected intraperitoneally to rats at a dose of $6 \mathrm{mg} / \mathrm{kg}$ body weight (Kawada et al. 1986b). However, the value returns to the basal level within $90 \mathrm{~min}$ and declines below basal levels by 120 min after the injection (Kawada 
et al. 1986b). In our previous study RQ was significantly increased after the RP diet from 50 to 150 min (Yoshioka et al. 1995). We considered that the difference between Kawada's study (Kawada et al. 1986b) and our previous study (Yoshioka et al. 1995) may be due to the differences in the composition of the diet: they used a HF diet but we used a $\mathrm{HC}$ diet. In addition, the former was performed in rats whereas we tested human subjects in our previous study. In the present study, postprandial RQ was decreased immediately after RP consumption in both the HC and HF meal conditions. However, no change was found for the rest of the experimental period after the $\mathrm{HC}$ meal whereas RQ was reduced for up to $150 \mathrm{~min}$ after the HF meal. These results suggest that the RQ response to the SNS stimulation by dietary RP depends on the composition of diet ( $\mathrm{HC}$ or $\mathrm{HF}$ ) which is consumed together with RP.

Comparison of results of our previous study (Yoshioka et al. 1995) with those for RQ after the HC and HC-RP meals in the present study might suggest a sex difference in the response to RP. From 60 to $150 \mathrm{~min}$ RQ was increased by the addition of RP to the $\mathrm{HC}$ meal in Japanese men whereas no change was found in Japanese women. It has been demonstrated that the skeletal muscle of women is characterized by a higher percentage of type I fibres compared with that of men (Simoneau et al. 1985) and that type I fibres show a threefold greater $\beta$-adrenergic receptor density than type II fibres of the same muscle. These findings suggest that the $\beta$-adrenergic stimulation in the skeletal muscle of women by the consumption of RP may be greater than in men. Moreover, Ellis et al. (1994) showed that oestradiol administration to male rats increased muscle lipoprotein lipase (EC 3.1.1.34; LPL) activity, which led to an increased distribution of plasma triacylglycerolderived fatty acids toward muscle. When RP was administered, plasma catecholamine concentrations tended to be increased (Lim et al. 1997). Since catecholamines (Miller et al. 1989) and cAMP (Palmer et al. 1990) are known to increase LPL activity in skeletal muscle, the effect of dietary RP may be due to the increase in muscle LPL activity which is stimulated by catecholamines. Furthermore, it is well known that a HF diet stimulates insulin secretion less than a $\mathrm{HC}$ diet and that insulin decreases muscle LPL activity (Boivin et al. 1994). Erskine et al. (1994) reported that muscle LPL activity was stimulated by HF-meal feeding but was suppressed by HC-meal feeding. Therefore, in the short term, it seems that SNS stimulation together with a HF diet maximizes the muscle LPL activity, resulting in an increase in lipid utilization in women.

Tappy et al. (1995) have suggested that it might be possible to improve the impaired lipid oxidation seen with a HF diet by stimulating the SNS in the postprandial state. In the present study, the addition of RP to the HF meal increased diet-induced lipid oxidation. Thus, these results indicate that RP increases lipid oxidation in women and that this increase in lipid oxidation is observed when the diet has a HF content.

In summary, we have investigated the effects of RP added to $\mathrm{HF}$ and $\mathrm{HC}$ meals on postprandial energy and substrate metabolism. The results indicate that RP increases DIT and lipid oxidation and that this increase in lipid oxidation is mainly observed when foods have a high fat content, whereas an increase in the perceived oiliness of the meal is found when RP is added to high-carbohydrate meals.

\section{Acknowledgements}

We express our grateful appreciation to Dr J. A. Simoneau for the discussion of this manuscript. This work was supported by the National Sciences and Engineering Research Council (Canada).

\section{References}

Abbott WGH, Howard BV, Ruotolo G \& Ravussin E (1990) Energy expenditure in humans: effects of dietary fat and carbohydrate. American Journal of Physiology 258, E347E351.

Acheson KJ, Jéquier E \& Wahren J (1983) Influence of betaadrenergic blockade on glucose-induced thermogenesis in man. Journal of Clinical Investigation 72, 981-986.

Acheson KJ, Ravussin E \& Wahren J (1984) Thermic effects of glucose in man: obligatory and facultative thermogenesis. Journal of Clinical Investigation 74, 1572-1580.

Acheson KJ, Schutz Y, Bessard T, Anantharaman K, Flatt J-P \& Jéquier $\mathrm{E}$ (1988) Glycogen storage capacity and de novo lipogenesis during massive carbohydrate overfeeding in man. American Journal of Clinical Nutrition 48, 240-247.

Behnke AR \& Wilmore JH (1974) Evaluation and Regulation of Body Build and Composition, pp. 20-37. Englewood Cliffs, NJ: Prentice-Hall.

Bennett C, Reed GW, Peters JC, Abumrad NN, Sun M \& Hill JO (1992) Short-term effects of dietary-fat ingestion on energy expenditure and nutrient balance. American Journal of Clinical Nutrition 55, 1071-1077.

Boivin A, Montplaisir I \& Deshaies Y (1994) Postprandial modulation of lipoprotein lipase in rats with insulin resistance. American Journal of Physiology 267, E620-E627.

Drewnowski A \& Greenwood MRC (1983) Cream and sugar: human preferences for high-fat foods. Physiology and Behaviour 30, 629-633.

Drewnowski A, Kurth C, Holden-Wiltse J \& Saari J (1992) Food preferences in human obesity: carbohydrates vs fats. Appetite 18, 207-221.

Duncan KH, Bacon JA \& Weinsier RL (1983) The effects of high and low energy density diets on satiety, energy intake, and eating time of obese and nonobese subjects. American Journal of Clinical Nutrition 37, 763-767.

Ellis GS, Lanza-Jacoby S, Gow A \& Kendrick ZV (1994) Effects of estradiol on lipoprotein lipase activity and lipid availability in exercised male rats. Journal of Applied Physiology 77, 209-215.

Erskine JM, Jensen DR \& Eckel RH (1994) Macronutrient regulation of lipoprotein lipase is posttranslational. Journal of Nutrition 124, 500-507.

Flatt JP, Ravussin E, Acheson KJ \& Jéquier E (1985) Effects of dietary fat on postprandial substrate oxidation and on carbohydrate and fat balances. Journal of Clinical Investigation 76, 1019-1024.

Hill AJ \& Blundell JE (1986) The effects of a high-protein or highcarbohydrate meal on subjective motivation to eat and food preferences. Nutrition and Behavior 3, 133-144.

Hill JO, Lin D, Yakubu F \& Peters JC (1992) Development of dietary obesity in rats: influence of amount and composition of dietary fat. International Journal of Obesity 16, 321-333.

Hill JO, Peters JC, Reed GW, Schlundt DG, Sharp T \& Greene HL 
(1991) Nutrient balance in humans: effects of diet composition. American Journal of Clinical Nutrition 54, 10-17.

Horton TJ, Drougas H, Brachey A, Reed GW, Peters JC \& Hill JO (1995) Fat and carbohydrate overfeeding in humans: different effects on energy storage. American Journal of Clinical Nutrition 62, 19-29.

Kawada T, Hagihara K \& Iwai K (1986a) Effects of capsaicin on lipid metabolism in rats fed a high fat diet. Journal of Nutrition 116, 1272-1278.

Kawada T, Sakabe S, Aoki N, Watanabe T, Higeta K, Iwai K \& Sugimoto E (1991) Intake of sweeteners and pungent ingredients increases the thermogenin content in brown adipose tissue of rat. Journal of Agricultural and Food Chemistry 39, 651-654.

Kawada T, Sakabe S, Watanabe T, Yamamoto M \& Iwai K (1988) Some pungent principles of spices cause the adrenal medulla to secrete catecholamine in anesthetized rats. Proceedings of the Society for Experimental Biology and Medicine 188, 229-233.

Kawada T, Watanabe T, Takaishi T, Tanaka T \& Iwai K (1986b) Capsaicin-induced beta-adrenergic action on energy metabolism in rats: influence of capsaicin on oxygen consumption, the respiratory quotient, and substrate utilization. Proceedings of the Society for Experimental Biology and Medicine 183, 250-256.

Leaf A \& Weber PC (1987) A new area for science in nutrition. American Journal of Clinical Nutrition 45, 1048-1053.

Lim K, Yoshioka M, Kikuzato S, Kiyonaga A, Tanaka H, Shindo M \& Suzuki M (1997) Dietary red pepper ingestion increased carbohydrate oxidation at rest and during exercise in runners. Medicine and Science in Sports and Exercise 29, 355-361.

Lissner L, Levitsky DA, Strupp BJ, Kalkwarf HJ \& Roe DA (1987) Dietary fat and the regulation of energy intake in human subjects. American Journal of Clinical Nutrition 46, 886-892.

Lusk G (1931) In The Elements of the Science of Nutrition, pp. 6174. London: Saunders.

Meneely GR \& Kaltreider NL (1949) Volume of the lung determined by helium dilution. Journal of Clinical Investigation $\mathbf{2 8}$, $128-139$.

Miller WC, Gorski J, Oscai LB \& Palmer WK (1989) Epinephrine activation of the heparin-nonreleasable lipoprotein lipase in three skeletal muscle fiber types of the rat. Biochemical and Biophysical Research Communications 164, 615-619.

Oscai LB, Brown MM \& Miller WC (1984) Effect of dietary fat on food intake, growth, and body composition in rats. Growth $\mathbf{4 8}$, 415-424.

Palmer WK, Oscai RA, Bechtel PJ \& Fisher GA (1990) Dibutyryl cAMP-induced increases in triacylglycerol lipase activity in developing L8 myotube cultures. Canadian Journal of Physiology and Pharmacology 68, 689-693.

Porikos KP, Booth G \& Van Italie TB (1977) Effect of covert nutritive dilution on the spontaneous food intake of obese individuals: a pilot study. American Journal of Clinical Nutrition 30, 1638-1644.

Raben A, Christensen NJ, Madsen J, Holst JJ \& Astrup A (1994) Decreased postprandial thermogenesis and fat oxidation but increased fullness after a high-fiber meal compared with a low-fiber meal. American Journal of Clinical Nutrition 59, $1386-1394$
Romieu I, Willett WC, Stampfer MJ, Colditz GA, Sampson L, Rosner B, Hennekens CH \& Speizer FE (1988) Energy intake and other determinants of relative weight. American Journal of Clinical Nutrition 47, 406-412.

Schutz Y, Flatt JP \& Jéquier E (1989) Failure of dietary fat intake to promote fat oxidation: a factor favoring the development of obesity. American Journal of Clinical Nutrition 50, 307-314.

Schutz Y \& Tremblay A (1991) Does lipid oxidation differ in gynoid and android obese women? International Journal of Obesity 16, 67-69.

Simoneau JA, Lortie G, Boulay MR, Thibault M-C, Thériault G \& Bouchard C (1985) Skeletal muscle histochemical and biochemical characteristics in sedentary male and female subjects. Canadian Journal of Physiology and Pharmacology 63, 30-35.

Siri WE (1956) The gross composition of the body. Advances in Biological and Medical Physics 4, 239-280.

Tappy L, Girardet K, Schwaller N, Vollenweider L, Jéquier E, Nicod P \& Scherrer U (1995) Metabolic effects of an increase in sympathetic activity in healthy humans. International Journal of Obesity 19, 419-422.

Thomas CD, Peters JC, Reed GW, Abumrad NN, Sun M \& Hill JO (1992) Nutrient balance and energy expenditure during ad libitum feeding of high-fat and high-carbohydrate diets in humans. American Journal of Clinical Nutrition 55, 934-942.

Tremblay A, Lavallée N, Alméras N, Allard L, Després JP \& Bouchard C (1991) Nutritional determinants of the increase in energy intake associated with a high-fat diet. American Journal of Clinical Nutrition 53, 1134-1137.

Tremblay A, Plourde G, Després JP \& Bouchard C (1989) Impact of dietary fat content and fat oxidation on energy intake in humans. American Journal of Clinical Nutrition 49, 799-805.

Warwick ZS \& Schiffmann SS (1992) Role of dietary fat in calorie intake and weight gain. Neuroscience and Biobehavioral Reviews 16, 585-596.

Watanabe T, Kawada T \& Iwai K (1987a) Enhancement by capsaicin of energy metabolism in rats through secretion of catecholamine from adrenal medulla. Agricultural and Biological Chemistry 51, 75-79.

Watanabe T, Kawada T \& Iwai K (1988a) Effect of capsaicin pretreatment on capsaicin-induced catecholamine secretion from the adrenal medulla in rat. Proceedings of the Society for Experimental Biology and Medicine 187, 370-374.

Watanabe T, Kawada T, Kurosawa M, Sato A \& Iwai K (1988b) Adrenal sympathetic efferent nerve and catecholamine secretion excitation caused by capsaicin in rats. American Journal of Physiology 255, E23-E27.

Watanabe T, Kawada T, Yamamoto M \& Iwai K (1987b) Capsaicin, a pungent principle of hot red pepper, evokes catecholamine secretion from the adrenal medulla of anesthetized rats. Biochemical and Biophysical Research Communications 142, 259-264.

Yoshioka M, Lim K, Kikuzato S, Kiyonaga A, Tanaka H, Shindo M \& Suzuki M (1995) Effects of red-pepper diet on the energy metabolism in men. Journal of Nutritional Science and Vitaminology 41, 647-656. 